\title{
Characterization and Fate of Hydrogen-Bonded Free-Radical Intermediates and Their Coupling Products from the Hydrogen Atom Transfer Agent 1,8-Naphthalenediol
}

\author{
Paola Manini, ${ }^{*}+\odot$ Massimo Bietti, ${ }^{\ddagger}{ }^{\dagger}$ Marco Galeotti, ${ }^{\ddagger}$ Michela Salamone, ${ }^{\ddagger}$ Osvaldo Lanzalunga, ${ }^{\S}$
} Martina M. Cecchini, ${ }^{\|}$Samantha Reale, ${ }^{\| \odot}$ Orlando Crescenzi, ${ }^{\dagger}$ Alessandra Napolitano, ${ }^{\dagger}$

Francesco De Angelis, "Vincenzo Barone, ${ }^{\perp \bullet}$ and Marco d'Ischia ${ }^{\dagger}{ }^{\circledR}$

${ }^{\dagger}$ Dipartimento di Scienze Chimiche, Università di Napoli Federico II, Via Cintia 4, I-80126 Napoli, Italy

‡Dipartimento di Scienze e Tecnologie Chimiche, Università “Tor Vergata”, Via della Ricerca Scientifica 1, I-00133 Rome, Italy

${ }^{\S}$ Dipartimento di Chimica e Istituto CNR di Metodologie Chimiche (IMC-CNR), Sezione Meccanismi di Reazione, Università di Roma "La Sapienza", P.le A. Moro 5, I-00185 Roma, Italy

"Dipartimento di Scienze Fisiche e Chimiche, Università dell'Aquila, Via Vetoio, L’Aquila I-67100, Coppito, Italy

${ }^{\perp}$ Scuola Normale Superiore, Piazza dei Cavalieri 7, I-56126 Pisa, Italy

\section{Supporting Information}

\begin{abstract}
Naphthalenediol (dihydroxynaphthalene, $1,8-\mathrm{DHN}$ ) has been shown to be a potent hydrogen atom transfer (HAT) antioxidant compound because of the strong stabilization of the resulting free radical by intramolecular hydrogen bonding. However, the properties, reactivity, and fate of the 1,8-DHN phenoxyl radical have remained so far uncharted. Herein, we report an integrated experimental and computational characterization of the early intermediates and dimer products that arise by the oxidation of $1,8-\mathrm{DHN}$. Laser flash photolysis (LFP) studies of HAT from 1,8-DHN to the cumyloxyl and aminoxyl radicals showed the generation of a transient species absorbing at 350, 400, and $>600 \mathrm{~nm}$ attributable to the $1,8-\mathrm{DHN}$ phenoxyl radical. Peroxidase/

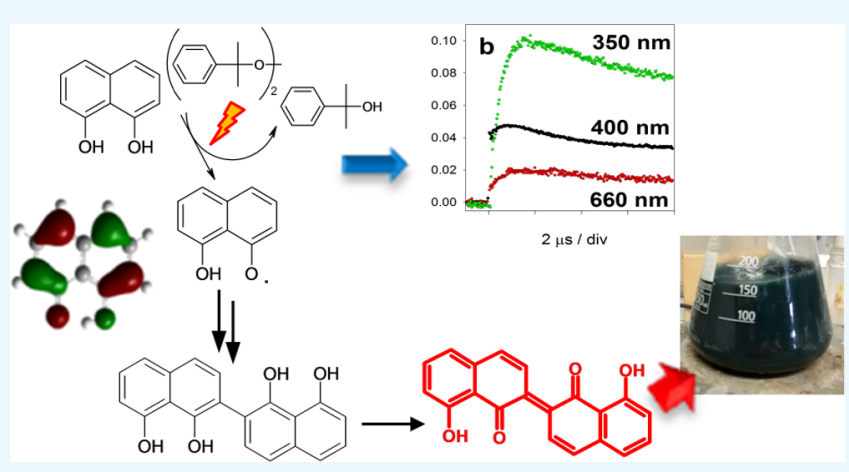
$\mathrm{H}_{2} \mathrm{O}_{2}$ oxidation of $1,8-\mathrm{DHN}$ was found to proceed via an intense blue intermediate $\left(\lambda_{\max } 654 \mathrm{~nm}\right)$ preceding precipitation of a black melanin-like polymer. By halting the reaction in the early stages, three main dimers featuring $2,2^{\prime}$-, $2,4^{\prime}$-, and $4,4^{\prime}$-bondings could be isolated and characterized in pure form. Density functional theory calculations supported the generation of the 1,8 DHN phenoxyl radical and its subsequent coupling via the 2- and 4-positions giving extended quinone dimers with intense transitions in the visible range, consistent with UV-vis and LFP data. Overall, these results allowed to elucidate the mechanism of oxidative polymerization of 1,8-DHN of possible relevance to melanogenesis in fungi and other processes of environmental and astrochemical relevance.
\end{abstract}

\section{INTRODUCTION}

1,8-Naphthalenediol or dihydroxynaphthalene $(1,8-\mathrm{DHN})$ is a naturally occurring polyketide derivative involved in the biosynthesis of black melanin polymers implicated in virulence, resistance to environmental stress, and protection against oxidative stress and harmful radiations in several fungi species. $^{1-4} 1,8-\mathrm{DHN}$ is also a possible component of the polycyclic aromatic hydrocarbon (PAH) derivatives that may be generated during combustion and other processes of high environmental impact that may contribute to pollution via polymerization mechanisms. ${ }^{5,6}$ In addition, 1,8-DHN and other hydroxylated $\mathrm{PAH}$ derivatives can be generated by the exposure of naphthalene to ultraviolet radiation in astrophysical ice analogs, allowing specific prediction of the existence and possible roles of various oxidized naphthalenes in planetary environments of possible prebiotic relevance. ${ }^{7-12}$

Previous studies indicated that $1,8-\mathrm{DHN}$ is a highly efficient antioxidant, as denoted by potent hydrogen atom transfer (HAT) properties determined by the 2,2-di(4-octylphenyl)-1picrylhydrazyl radical and the azobisisobutyronitrile-initiated styrene autoxidation assays. ${ }^{13}$ The antioxidant behavior was attributed to (a) the large stabilizing effect of the resulting aryloxyl radical by intramolecular hydrogen bonding and (b) the additional stabilization of the $\mathrm{H}$-bonded intermediate by the naphthalene ring system. Both kinetic experiments and

Received: January 24, 2018

Accepted: March 26, 2018

Published: April 6, 2018 
theoretical calculations of the $\mathrm{O}-\mathrm{H}$ bond dissociation enthalpies revealed the more effective antioxidant power exhibited by $1,8-\mathrm{DHN}$ with respect to the parent phenolic and/or catecholic compounds. ${ }^{14-17}$ Possible exploitation as an antioxidant was moreover suggested by its inability to form a quinone because of the meta-like peri dioxygenation pattern, making its oxidation products expectedly less toxic. Although the HAT process from 1,8-DHN has been extensively investigated, little information is currently available about the properties and chemical fate of the resulting $\mathrm{H}$-bonded radical. In this connection, a systematic mass spectrometric investigation of the biomimetic polymerization of 1,8-DHN with horseradish peroxidase (HRP) $/ \mathrm{H}_{2} \mathrm{O}_{2}$ or laccase in phosphate buffer at $\mathrm{pH} 7$ showed in both cases $\mathrm{C}-\mathrm{C}$ coupling of the naphthalene rings as the dominant mode of coupling. ${ }^{18}$ However, the properties and mode of coupling of the $\mathrm{H}$ bonded phenoxyl radical, the nature of the main oligomer intermediates, and the mechanism of the polymerization process beyond the dimer level remained virtually unexplored.

Herein, we report a combined experimental and theoretical investigation aimed at characterizing by laser flash photolysis (LFP) the early transient species produced by the oxidation of 1,8 -DHN and monitoring their conversion into isolable oligomer intermediates. Specific aims of the study were as follows: (a) to probe the kinetics and the course of HAT processes from 1,8 -DHN by an approach complementary to those reported in the literature and to characterize the resulting free-radical species; (b) to identify the main chromophoric species produced in the process; and (c) to assess the mode of coupling of H-bonded phenoxyl radicals via isolation and characterization of dimer intermediates. Both transient product identification and mechanistic analysis were supported by extensive density functional theory (DFT) calculations.

\section{RESULTS AND DISCUSSION}

LFP Experiments. The absorption properties and kinetics of the species produced from 1,8-DHN under HAT conditions were investigated by the cumyloxyl radical $\left(\mathrm{CumO}^{\bullet}\right)$ and two $\mathrm{N}$-oxyl radicals such as phthalimide- $\mathrm{N}$-oxyl (PINO) and benzotriazole- $N$-oxyl radical (BTNO) as the abstracting species. $\mathrm{CumO}^{\bullet}$ was generated by $355 \mathrm{~nm}$ LFP of acetonitrile solutions containing dicumyl peroxide (Scheme 1). ${ }^{19}$

Scheme 1. Generation of the Cumyloxyl Radical by LFP and Its Action on $1,8-\mathrm{DHN}^{20}$

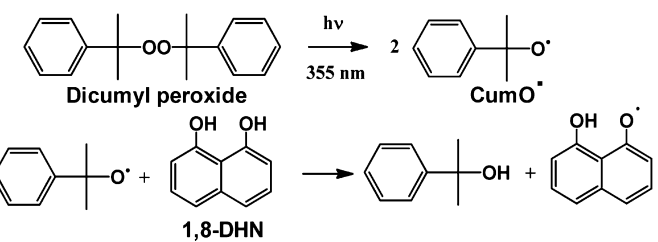

For comparative purposes, to aid in the identification of the main transient species and to probe the effect of intramolecular hydrogen bonding, the same experiments were run on 1,5dihydroxynaphthalene $(1,5-\mathrm{DHN})$, which produces on oxidation a quinone-type intermediate, and on 1-naphthol, which bears a single $\mathrm{OH}$ group. Figure 1 shows the spectral changes observed following $355 \mathrm{~nm}$ LFP of an acetonitrile solution containing dicumyl peroxide and 1,8-DHN (1), 1,5-DHN (2), or 1-naphthol (3).

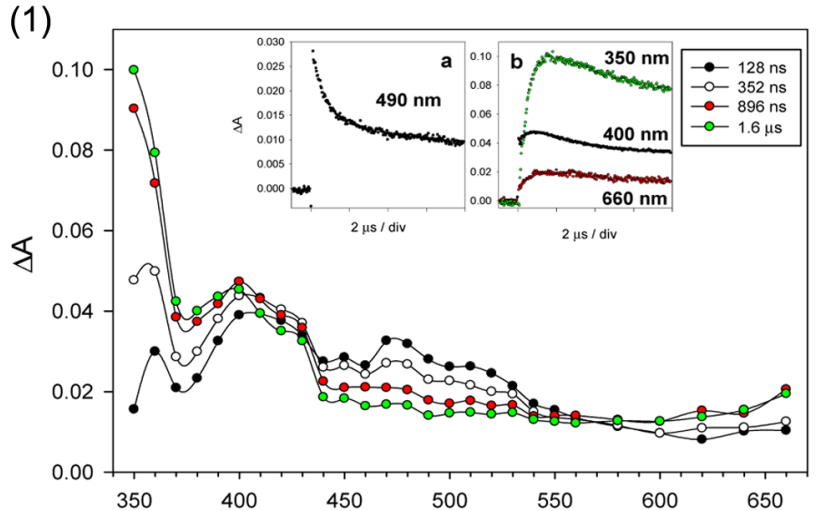

(2)

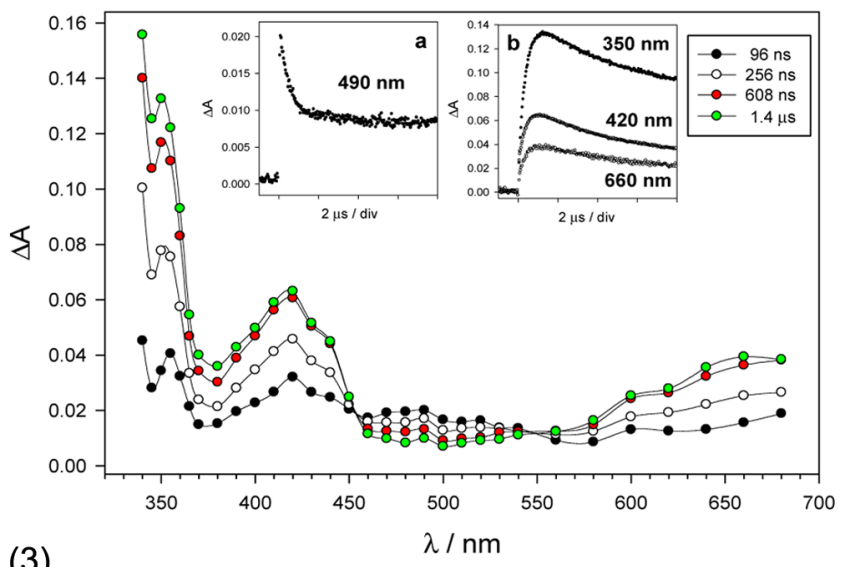

(3)

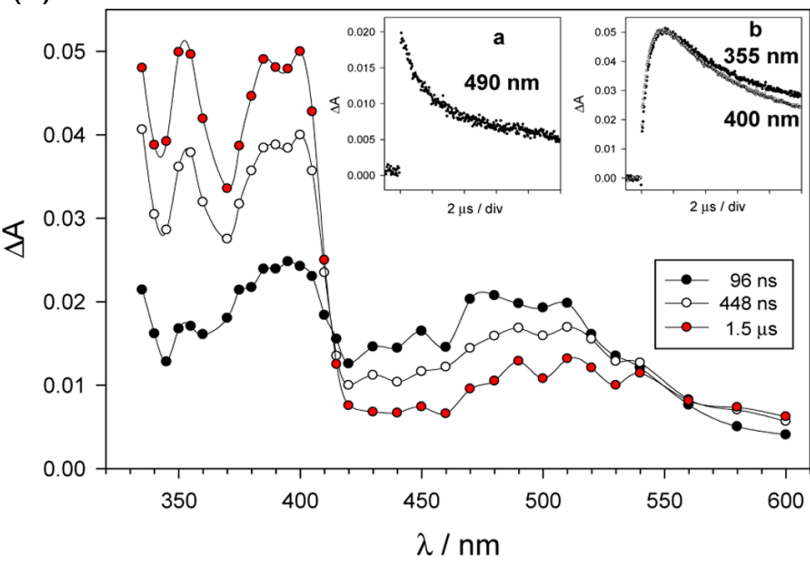

Figure 1. Time-resolved absorption spectra observed after $355 \mathrm{~nm}$ LFP of an argon-saturated $\mathrm{MeCN}$ solution $\left(T=25{ }^{\circ} \mathrm{C}\right)$ containing dicumyl peroxide $(1.0 \mathrm{M})$ and 1,8-DHN $(3.0 \mathrm{mM})(\mathbf{1}), 1,5-\mathrm{DHN}(4.9$ $\mathrm{mM})(2)$, or 1-naphthol $(7.7 \mathrm{mM})(3)$ recorded at various time after the $8 \mathrm{~ns}, 10 \mathrm{~mJ}$ laser pulse. Insets: (a) Decay of the cumyloxyl radical monitored at $490 \mathrm{~nm}$ and (b) buildup and subsequent decay of absorption monitored at various wavelengths.

In the case of $1,8-\mathrm{DHN}$, the decay of $\mathrm{CumO}^{\bullet}$ monitored at $490 \mathrm{~nm}$ was accompanied by the buildup of a transient species characterized by three absorption bands centered at 350, 400, and $>660 \mathrm{~nm}$, which can be assigned to the 8-hydroxy-1naphthoxyl radical produced by HAT. Comparative inspection of the traces obtained from 1,5-DHN and 1-naphthol as reference substrates under the same conditions showed a markedly different profile only in the case of 1-naphthol. ${ }^{21}$ This observation indicated that the contribution of the second $\mathrm{OH}$ group on the adjacent ring was more important than 
intramolecular H-bonding in determining the free-radical absorption properties.

The second-order rate constants $\left(k_{\mathrm{H}}\right)$ for the reaction of $\mathrm{CumO}^{\bullet}$ with these substrates were obtained from the slope of the observed rate constant $\left(k_{\text {obs }}\right)$ versus [substrate] plots, where in turn, the $k_{\text {obs }}$ values were measured following the buildup of the naphthoxyl radical absorption band at the different substrate concentrations. The $k_{\mathrm{H}}$ values thus obtained show an almost threefold increase on going from mono to dihydroxynaphthalenes, with 1,8-DHN giving higher values than $1,5-\mathrm{DHN}$, confirming previously reported stabilizing effect of $\mathrm{H}$-bonding exerted by the peri $\mathrm{OH}$ group (Table 1 ).

Table 1. Second-Order Rate Constants $\left(k_{\mathrm{H}} / \mathrm{M}^{-1} \mathrm{~s}^{-1}\right)$ for the Reaction of the Cumyloxyl Radical with

Hydroxynaphthalenes, Measured in $\mathrm{MeCN}$ at $\mathrm{T}=25^{\circ} \mathrm{C}$

\begin{tabular}{|l|c|c|}
\hline Substrate & $\boldsymbol{\lambda}_{\text {monit }}$ & $\boldsymbol{k}_{\mathbf{H}}{ }^{\mathbf{a}}$ \\
\hline & $400 \mathrm{~nm}$ & $1.43 \pm 0.02 \times 10^{8}$ \\
\hline & & \\
\hline
\end{tabular}

${ }^{a}$ Measured following the buildup of the naphthoxyl radical absorption bands between 360 and $420 \mathrm{~nm}$. Average of two independent kinetic experiments.

HAT from 1,8-DHN was also investigated on the longer millisecond scale using two aminoxyl radicals, PINO and BTNO, which are significantly less reactive than $\mathrm{CumO}^{\bullet}$ as hydrogen atom abstractors. In the LFP experiments, PINO and BTNO were produced by HAT from $N$-hydroxyphthalimide and 1-hydroxybenzotriazole (HBT) to $\mathrm{CumO}^{\bullet}$ (Scheme 2), respectively, which in turn was generated as described above. ${ }^{22-26}$

Figure 2 shows the time-resolved absorption spectra observed after $355 \mathrm{~nm}$ LFP of an argon-saturated MeCN solution containing dicumyl peroxide (1.0 M), HBT (9.2 mM), and 1,8-DHN (0.57 $\mathrm{mM})$.

The decay of the BTNO radical followed at the maximum absorption wavelength $(480 \mathrm{~nm})^{27}$ occurs on the millisecond timescale and is accompanied by the formation of a species characterized by an absorption maximum around $370 \mathrm{~nm}$ that does not decay in this time regime. Because the lifetime of the naphthoxyl radical formed following HAT from 1,8-DHN was
Scheme 2. Generation of PINO and BTNO by LFP and Their Action on 1,8-DHN
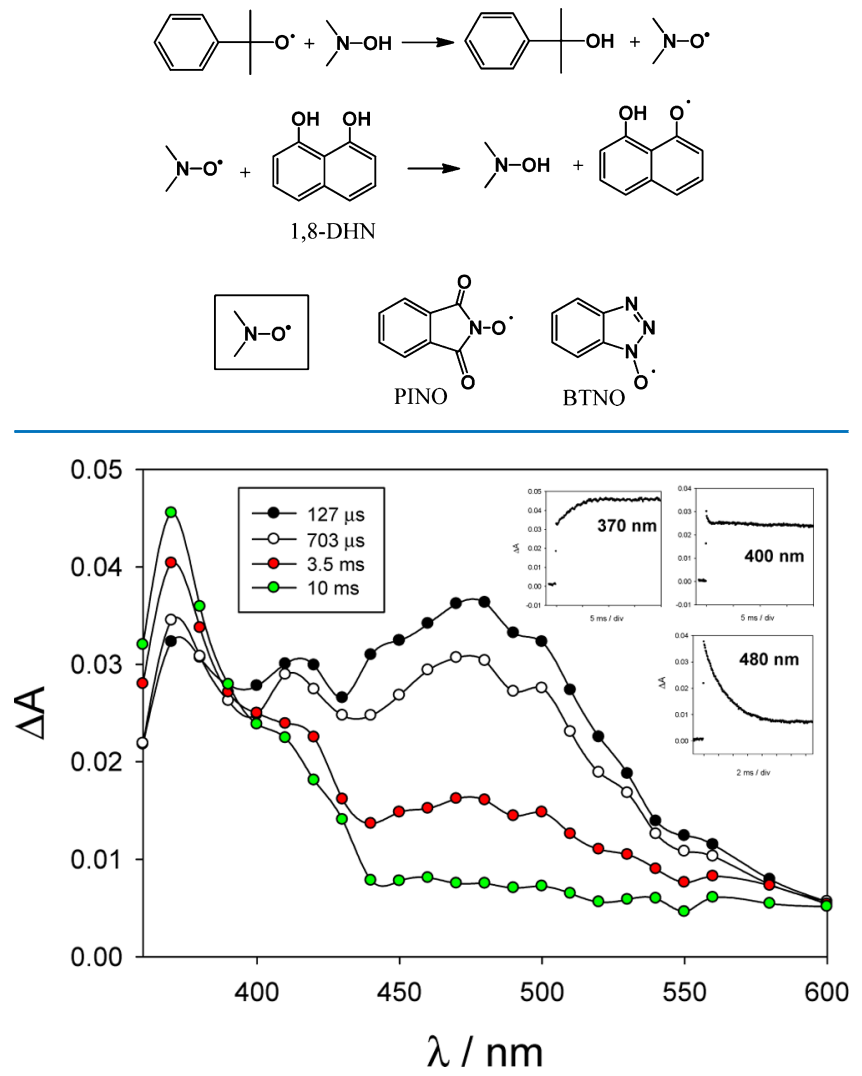

Figure 2. Time-resolved absorption spectra observed after $355 \mathrm{~nm}$ LFP of an argon-saturated $\mathrm{MeCN}$ solution $\left(T=25^{\circ} \mathrm{C}\right)$ containing dicumyl peroxide $(1.0 \mathrm{M})$, HBT $(9.2 \mathrm{mM})$, and 1,8-DHN $(0.57 \mathrm{mM})$ recorded at $127 \mu \mathrm{s}$ (black circles), $703 \mu \mathrm{s}$ (white circles), $3.5 \mathrm{~ms}$ (red circles), and $10 \mathrm{~ms}$ (green circles) after the $8 \mathrm{~ns}, 10 \mathrm{~mJ}$ laser pulse. Insets: Buildup of absorption monitored at $370 \mathrm{~nm}$; buildup and subsequent decay of absorption monitored at $400 \mathrm{~nm}$; and decay of absorption monitored at $480 \mathrm{~nm}$.

too short to allow its detection on this timescale (Figure 1(1), inset $\mathrm{b}$ ), the species absorbing at $370 \mathrm{~nm}$ was tentatively assigned to a coupling product derived from dimerization of the 1,8-DHN phenoxyl radical. Support to this hypothesis was provided by the observation of a similar spectrum, characterized by an absorption band centered at $370 \mathrm{~nm}$, when the reaction of $\mathrm{CumO}^{\bullet}$ with $1,8-\mathrm{DHN}$ was analyzed $1 \mathrm{~ms}$ after the laser pulse, that is, at a significantly longer time delay as compared to those of the spectra displayed in Figure 1 (see Figures S10 and S11).

Using an excess of the substrate under pseudo-first-order conditions, the observed rate constants $\left(k_{\text {obs }}\right)$ were measured following the decay of PINO or BTNO at their maximum absorption wavelengths (380 and $480 \mathrm{~nm}$, respectively)..$^{27,28}$ From the slope of the $k_{\text {obs }}$ versus [substrate] plots, the $k_{\mathrm{H}}$ values for HAT from 1-naphthol, 1,5-DHN, and 1,8-DHN to PINO and BTNO were determined. The rate constants thus obtained are collected in Table 2. $k_{\mathrm{H}}$ values are in line with those determined in a previous study for HAT from activated phenolic systems. $^{29,30}$

As observed for HAT promoted by $\mathrm{CumO}^{\bullet}$, the measured $k_{\mathrm{H}}$ values increased on going from mono to dihydroxynaphthalenes, with 1,5-DHN proving less reactive than $1,8-\mathrm{DHN}$. 
Table 2. Second-Order Rate Constants $\left(k_{\mathrm{H}} / \mathrm{M}^{-1} \mathrm{~s}^{-1}\right)$ for the Reaction of the PINO and BTNO Radicals with Hydroxynaphthalenes, Measured in $\mathrm{MeCN}$ at $\mathrm{T}=25^{\circ} \mathrm{C}$

\begin{tabular}{ccc} 
substrate & $k_{\mathrm{H}}(\mathrm{PINO})$ & $k_{\mathrm{H}}(\mathrm{BTNO})$ \\
1-naphthol & $5.5 \pm 0.3 \times 10^{4}$ & $3.5 \pm 0.5 \times 10^{4}$ \\
1,8-DHN & $1.2 \pm 0.1 \times 10^{6}$ & $5.1 \pm 0.1 \times 10^{5}$ \\
$1,5-\mathrm{DHN}$ & $2.9 \pm 0.2 \times 10^{5}$ & $2.60 \pm 0.1 \times 10^{5}$ \\
\hline
\end{tabular}

However, significantly larger differences were observed for the $\mathrm{N}$-oxyl radicals as compared to $\mathrm{CumO}^{\bullet}\left[k_{\mathrm{H}}(1,8-\mathrm{DHN}) / k_{\mathrm{H}}(1\right.$ naphthol $)=21.8,14.6$, and 2.7 for PINO, BTNO, and CumO ${ }^{\bullet}$, respectively], a behavior that reasonably reflects the lower intrinsic reactivity of the former radicals as compared to the latter one.

Some of the putative species accounting for the dynamic absorption measurements in Figures 1 and 2 with relevant absorption maximum are indicated below in Scheme 3 .

Scheme 3. Mechanism Accounting for the Formation of 1,8DHN Dimers

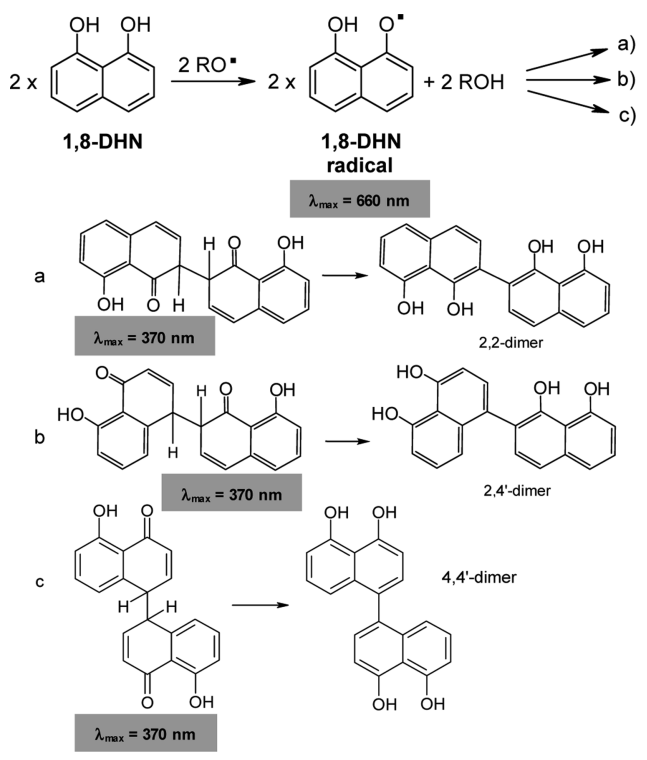

Oxidation Chemistry of 1,8-DHN: Isolation and Characterization of Oligomeric Intermediates. In subsequent experiments, $1,8-\mathrm{DHN}$ was oxidized with the HRP/ $\mathrm{H}_{2} \mathrm{O}_{2}$ system in phosphate buffer at $\mathrm{pH} 7,{ }^{18}$ and the course of the reaction was investigated by spectrophotometric analysis.

Data in Figure 3 show the rapid development of a visible absorbing species with a maximum at $654 \mathrm{~nm}$ and a shoulder at 583 accounting for an intense greenish-blue coloration persisting over $40 \mathrm{~min}$.

By halting the reaction via addition of sodium dithionite, followed by extraction with ethyl acetate and acetylation of the extractable fraction, it was possible to obtain, after a first chromatographic step, a mixture of dimeric products, as supported by ultraperformance liquid chromatography (UPLC)-electrospray ionization (ESI)-mass spectrometry (MS) and NMR evidence (Figure 4). Inspection of the twodimensional (2D) NMR spectra of the whole fraction allowed the identification of a set of resonances ascribable to the unsubstituted portion of the naphthalene ring (double doublets around $\delta 7.9$ and 7.2 and triplets at $\delta 7.5-7.6)$ along with sets of doublets attributable to monosubstituted aromatic rings
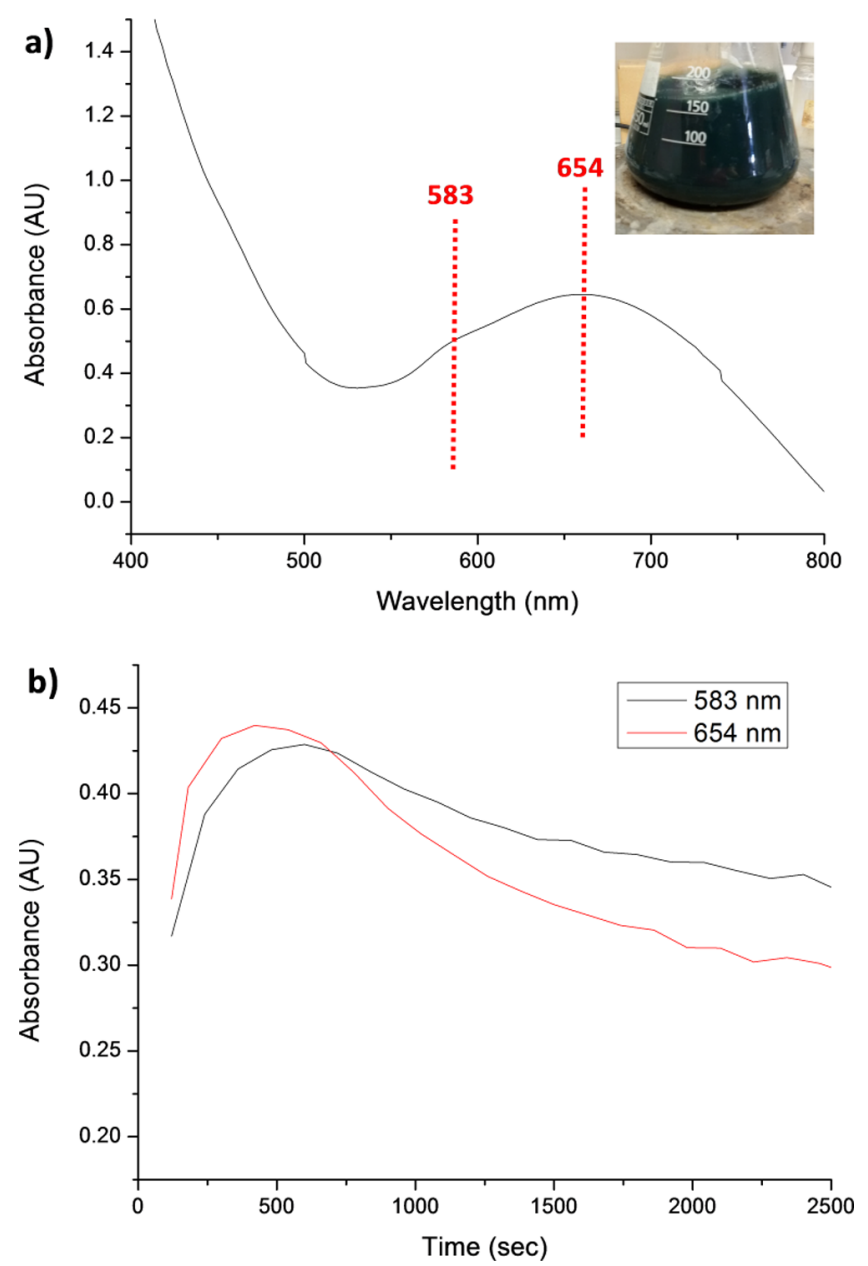

Figure 3. Visible absorption spectrum of the oxidation mixture of 1,8DHN after $10 \mathrm{~min}(\mathrm{a})$; inset: picture of the reaction mixture taken at the same time. Time evolution monitored at 583 and $654 \mathrm{~nm}$ (b).

(Figure S9). These assignments were supported by the analysis of the ${ }^{1} \mathrm{H},{ }^{13} \mathrm{C}$ heteronuclear single-quantum coherence and ${ }^{1} \mathrm{H},{ }^{13} \mathrm{C}$ heteronuclear multiple bond correlation spectra of the same fraction. By repeated chromatographic steps, three main products were isolated in pure form and identified by mono and bidimensional NMR analysis and by MS (Figures S1-S8) as the 2,2'-, 2,4'-, and 4,4'-dimers (Figure 4).

Mechanistic Issues and DFT Calculations. On the basis of spectrophotometric, LFP, and product isolation experiments, a number of important issues arose concerning: (1) the actual identification of the first formed species as the phenoxyl radicals; (2) the nature of the species responsible for the persistent blue-green coloration from 1,8-DHN; and (3) the prevalent mode of coupling of the free radical from $1,8-\mathrm{DHN}$ because the observed order of isolated yields could not be related in a straightforward manner to the regioselectivity of the initial free-radical coupling. In addition, it was of interest to understand the dominant mechanism of oligomer chain growth following the dimer stage to predict the nature of main oligomer building blocks in the final melanin-like polymer. To address these issues, a detailed computational investigation of the structural and spectroscopic properties of the main oxidation products of 1,8 -DHN was carried out at the DFT level of theory to address mechanistic issues and to corroborate the main structural conclusions from the preceding experiments. 

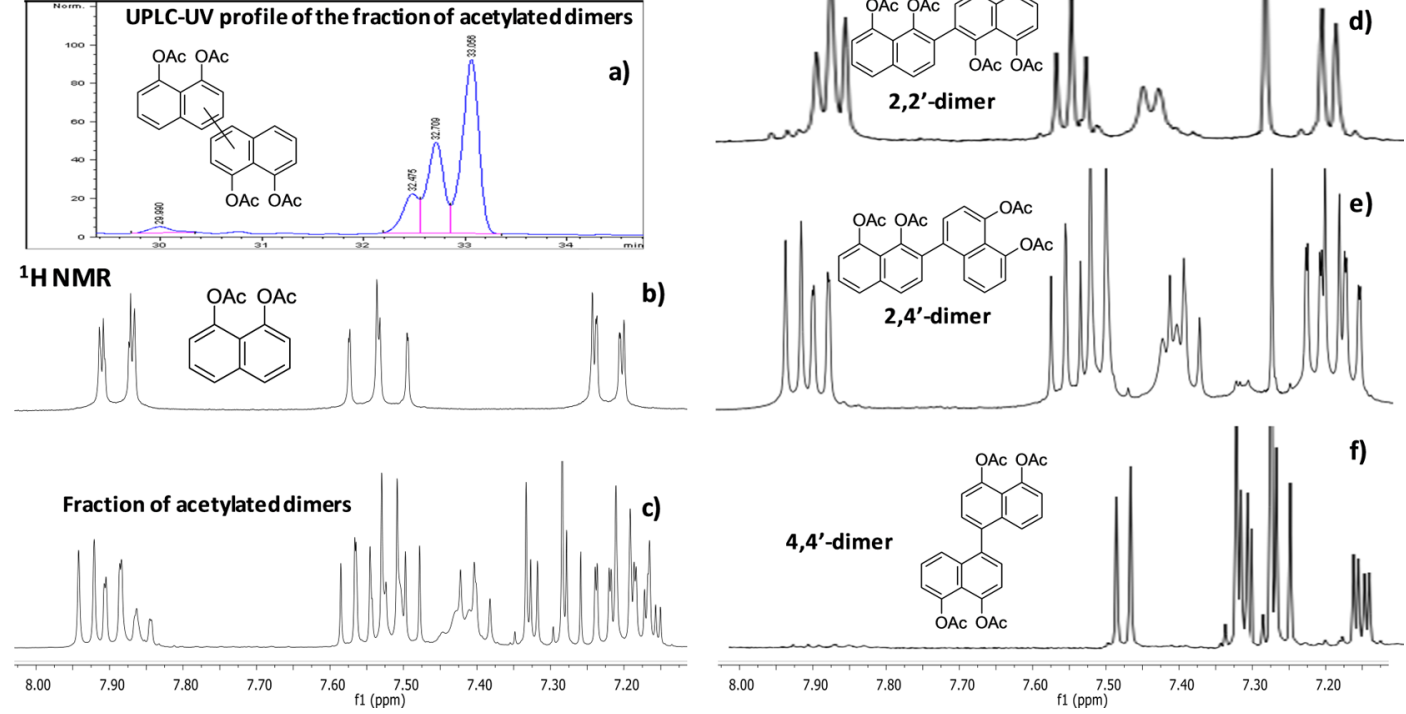

Figure 4. Isolation of the dimers of $1,8-\mathrm{DHN}$ under oxidative conditions. UPLC-UV profile of the fraction of acetylated dimers (a); and ${ }^{1} \mathrm{H}$ NMR (aromatic protons region) spectra of acetylated 1,8-DHN (b), the fraction of acetylated dimers (c), and the acetylated 2,2'- (d), 2,4'- (e), and 4,4'dimers (f).

Table 3. Computed (PBE0/6-31+G(d,p)/PCM) Properties of the 1,8-DHN Radical and Its Anion

\begin{tabular}{|c|c|c|c|c|c|}
\hline Bond distances / $\AA$ A & PG & SOMO & LUMO & Spin density & $\lambda / \mathrm{nm}(f)^{\mathrm{a}}$ \\
\hline (1.005 & $C_{s}$ & & & & $\begin{array}{l}675.5(0.06) ; \\
345.0(0.05) ; \\
309.5(0.12) ; \\
304.3(0.07)\end{array}$ \\
\hline (.380 & $\mathrm{C}_{2}$ & & & & $\begin{array}{l}977.8(0.06) ; \\
326.3(0.16) ; \\
311.6(0.09)\end{array}$ \\
\hline
\end{tabular}

${ }^{a}$ Selected $(\lambda>300 \mathrm{~nm}, f>0.05)$ electronic transitions (TD-PBE0/6-311++G(2d,2p)/PCM).

All structures were geometry-optimized at the DFT level, with a hybrid functional (PBE0) ${ }^{31}$ and a reasonably large basis set $[6-31+G(d, p)]$. For each species, different tautomers/ conformers, as well as different protonation states were explored. Computations were performed either in vacuo or by adoption of a polarizable continuum medium $(\mathrm{PCM})^{32-35}$ to account for the influence of the solution environment. Nonelectrostatic contributions to the solvation free energy were accounted for in single-point PCM calculations employing radii and nonelectrostatic terms of the SMD solvation model. ${ }^{36}$ Vibrational-rotational contributions to the free energy were also computed.

The issue of the regiochemistry of the initial coupling step was addressed by investigating the properties of the first-formed radical. A description of the most stable form of the $1,8-\mathrm{DHN}$ free radical [(8-hydroxynaphthalen-1-yl)oxidanyl] and its anion, including structural parameters, spin density, singly occupied molecular orbital (SOMO), and main electronic transitions with relevant oscillator strengths ${ }^{37-41}$ is given in Table 3 . The simulated absorption spectrum is given in Figure 5.

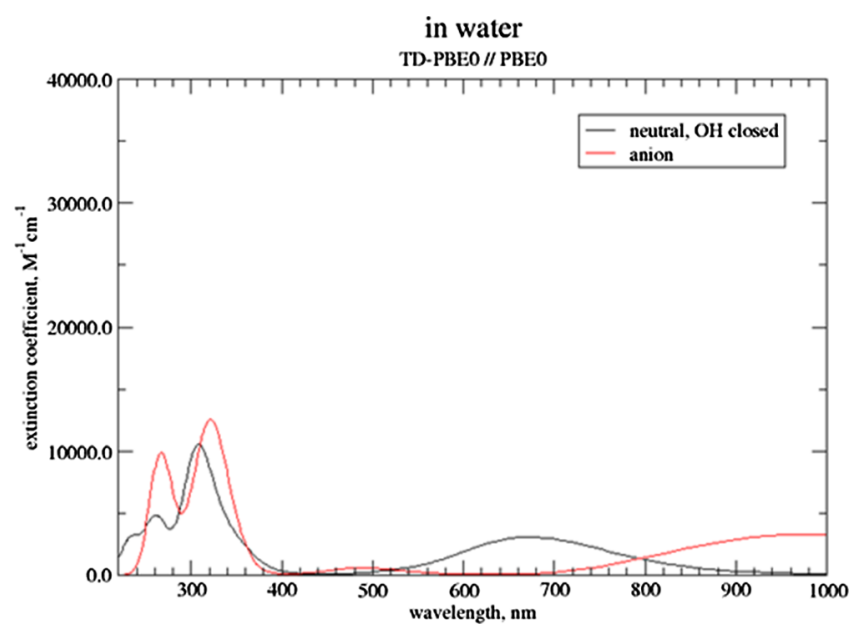

Figure 5. Simulated (TD-PBE0/6-311++G $(2 \mathrm{~d}, 2 \mathrm{p}) / \mathrm{PCM} / / \mathrm{PBE} 0 / 6-$ $31+\mathrm{G}(\mathrm{d}, \mathrm{p}) / \mathrm{PCM})$ absorption spectrum of the $1,8-\mathrm{DHN}$ radical and its anion. 
Inspection of the simulated spectra for the radical revealed distinct maxima predicted at ca. 320 and $670 \mathrm{~nm}$. These spectra matched fairly well with the trace of the developing species in the LFP experiment attributed to the initially formed free radical. The regioselectivity issue posed by the radical coupling step was then investigated by comparing the relative stability of the early coupling products prior to aromatization. The underlying assumption was that the free-radical dimerization step is under kinetic control and obeys to the Bell-EvansPolanyi principle, whereby dimer product distribution would be dictated by the energies of the transition states mirroring the relative stability of the isomeric $2,2^{\prime}$-, $2,4^{\prime}$-, and $4,4^{\prime}$-coupling products (Scheme 3).

Table 4 reports the energies computed for the most stable conformers of the isomeric coupling products. It appears that

Table 4. Relative Stabilities of Isomeric 1,8-DHN Coupling Products (Neutral Forms in Water, PBE0/6-31+G(d,p)/ PCM $)^{a}$

\begin{tabular}{lccc}
\multicolumn{1}{c}{ isomer } & most stable conformer & $\mathrm{PG}$ & $\mathrm{G}_{\mathrm{SMD}, \mathrm{RRHO}} / \mathrm{Ha}^{b}$ \\
$2,2^{\prime}, \mathrm{DL}$ & $\mathrm{T}, \mathrm{OH}$ closed & $C_{2}$ & $-1070.096322(0.4)$ \\
$2,2^{\prime}$, meso & G-, OH closed & $C_{1}$ & $-1070.096901(\mathbf{0 . 0})$ \\
$2,4^{\prime}, \mathrm{RR}$ & T, OH closed & $C_{1}$ & $-1070.095650(0.8)$ \\
$2,4^{\prime}, \mathrm{RS}$ & G-, OH closed & $C_{1}$ & $-1070.095064(1.2)$ \\
$4,4^{\prime}$, DL & T, OH closed & $C_{2}$ & $-1070.093814(1.9)$ \\
$4,4^{\prime}$, meso & G-, OH closed & $C_{1}$ & $-1070.092763(2.6)$
\end{tabular}

${ }^{a}$ In parentheses relative energies $\left(\mathrm{kcal} \mathrm{mol}^{-1}\right)$ referred to the most stable form (in bold). ${ }^{b}$ Free energy computed at the rigid rotor/ harmonic oscillator level, including SMD nonelectrostatic contributions.

the $2,2^{\prime}$-dimer is slightly more stable than the $2,4^{\prime}$ - and the $4,4^{\prime}$ dimers in that order.

The simulated absorption spectra of the coupling products are reported in Figure 6. For all, a similar absorption around $360 \mathrm{~nm}$ could be predicted. This maximum falls close to the absorption maximum found in the LFP experiments with the BTNO radical, thus supporting the assignment of the transient species formed in the LFP experiment to the dimers of 1,8 DHN.

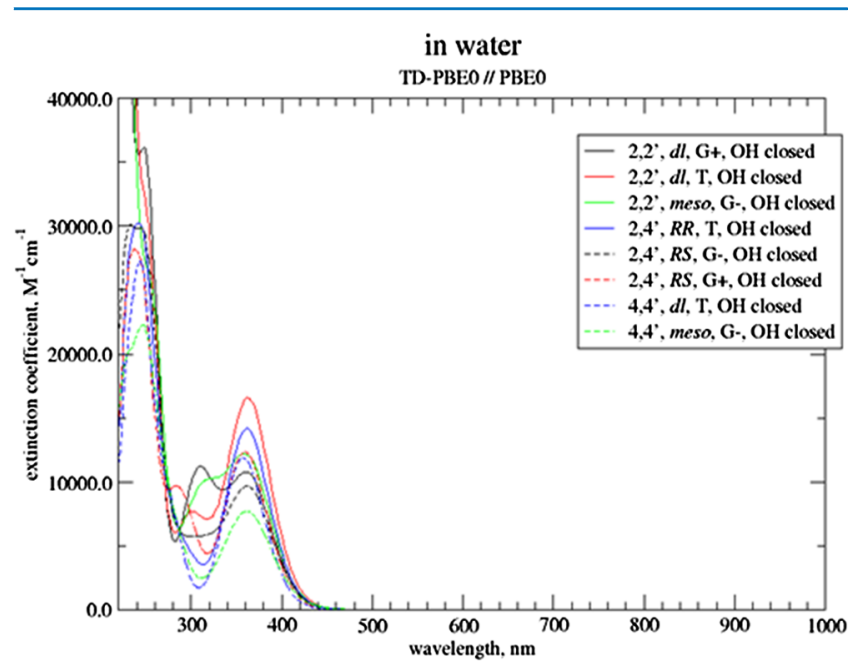

Figure 6. Simulated (TD-PBE0/6-311++G(2d,2p)/PCM//PBE0/6$31+\mathrm{G}(\mathrm{d}, \mathrm{p}) / \mathrm{PCM})$ absorption spectra of the most stable $1,8-\mathrm{DHN}$ coupling products.
To clarify the nature of the blue chromophoric species produced by $1,8-\mathrm{DHN}$ oxidation, the possible extended quinone forms arising from the dimers (Scheme 4) were then investigated and compared for their energy and absorption properties.

Scheme 4. Structures of the Quinone Forms Obtained from 1,8-DHN Dimers

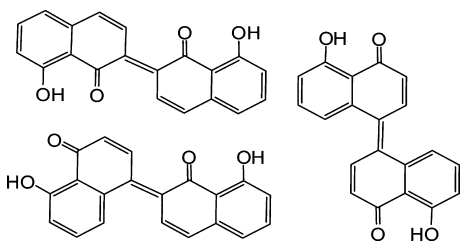

Table 5 reports the energies computed for the most stable conformers of the three isomeric extended quinone forms. As

Table 5. Relative Stabilities of Isomeric Extended Quinones from 1,8-DHN (Neutral Forms in Water, PBE0/6$31+\mathrm{G}(\mathrm{d}, \mathrm{p}) / \mathrm{PCM})^{a}$

$\begin{array}{cccc}\text { Isomer } & \text { most stable conformer } & \text { PG } & G_{\text {SMD,RRHO}} / \mathrm{Ha}^{b} \\ 2,2^{\prime}, E & \text { OH closed } & C_{2} & -\mathbf{1 0 6 8 . 9 0 4 0 3 0 ( 0 . 0 )} \\ 2,2^{\prime}, Z & \text { OH closed } & C_{2} & -1068.899453(2.9) \\ 2,4^{\prime}, E & \text { OH closed } & C_{1} & -1068.903454(0.4) \\ 2,4^{\prime}, Z & \text { OH closed } & C_{1} & -1068.900032(2.5) \\ 4,4^{\prime}, E & \text { OH closed } & C_{2} & -1068.902717(0.8) \\ 4,4^{\prime}, Z & \text { OH closed } & C_{2} & -1068.899257(3.0)\end{array}$

${ }^{a}$ In parentheses relative energies $\left(\mathrm{kcal} \mathrm{mol}^{-1}\right)$ referred to the most stable form (in bold). ${ }^{b}$ Free energy computed at the rigid rotor/ harmonic oscillator level, including SMD non-electrostatic contributions.

expected, the $E$ geometry along the inter-ring double bond is invariably favored.

More interestingly, the more favorable energetics associated with the 2,2' coupling mode at the dienedione level were confirmed at the higher extended quinone-type oxidation level. Inspection of the main electronic transitions predicted for these systems (Figure 7) revealed in all cases a consistent band in the $600-700 \mathrm{~nm}$ range, the largest bathochromic absorption being associated with the most stable $2,2^{\prime}$ isomer.

It is thus reasonably argued that the rapidly developing bluegreen stage of the reaction corresponds to the formation of extended quinone forms at the dimer level.

Finally, the most viable route for oligomer growth was preliminarily investigated. In principle, two possible pathways for trimer formation can be proposed, namely, (a) the generation of the radical from the dimer followed by coupling with the monomer free radical and (b) the nucleophilic addition of the monomer to the extended quinone of a dimer (Scheme 5).

The competition between the two reaction pathways would then be determined by the site of $\mathrm{H}$-atom abstraction from the dimer.

Oxidation of an $\mathrm{OH}$ group on the same ring involved in dimerization (Scheme 5, path b) would lead to a highly delocalized free radical that can be converted to the extended quinone supposedly via disproportionation or further oxidation. Conversely, in the case of free-radical formation from the $\mathrm{OH}$ group on the ring adjacent to that involved in dimerization 


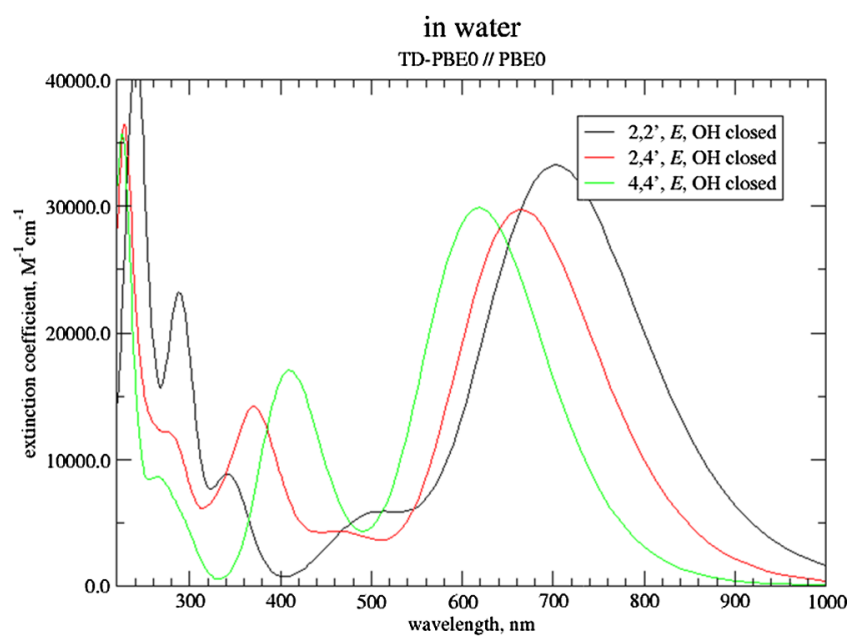

Figure 7. Simulated (TD-PBE0/6-311++G $(2 \mathrm{~d}, 2 \mathrm{p}) / \mathrm{PCM} / / \mathrm{PBE} 0 / 6-$ $31+\mathrm{G}(\mathrm{d}, \mathrm{p}) / \mathrm{PCM})$ absorption spectra of the most significant extended quinones.

(Scheme 5, path a), evolution toward the extended quinone would be precluded and free-radical coupling is the sole viable option. Other routes not supported by a solid literature may be envisaged, but they were not considered for the purposes of this study.

To assess which of the two pathways is the most likely, the relative energies of the free radicals produced by the two competing $\mathrm{H}$-atom abstraction pathways from the representative $2,2^{\prime}$-dimer were compared. The results definitively predicted path $b$ as the most favorable, based on the greater stability of the radical due to extended spin delocalization. No information about the ionic or radical competing pathways could be drawn from regiochemical considerations, both giving in principle the same species.

\section{CONCLUSIONS}

In conclusion, LFP and peroxidase oxidation experiments, though related to different conditions, have provided complementary information on the free-radical pathways of DHN oxidation. Whereas LFP yielded insight into the early transient species produced following HAT to the oxygencentered radicals, the peroxidase oxidation relevant to biological fungal pathways allowed the identification of the isolable oligomer intermediates downstream the initial oxidation step. Altogether, experimental and computational data demonstrated an initial free-radical coupling pathway of 1,8-DHN followed by additional radical coupling steps or alternative phenol-extended quinone coupling processes. The main findings can be summarized as follows:

(a) the initial event in 1,8-DHN oxidation is the generation of a naphthoxyl radical following HAT;

(b) isolation and spectral characterization of a dimeric fraction from the oxidation mixture of 1,8-DHN indicated the formation of mixtures of isomers arising from coupling through the 2- and 4-positions;

(c) predicted energies for free-radical coupling products support $2,2^{\prime}$-dimerization as the most favorable pathway though differences from the alternative $2,4^{\prime}$ - and $4,4^{\prime}$ routes are not large enough to justify a high degree of regioselectivity, consistent with the observed isomeric dimer composition;

(d) subsequent dimer-monomer coupling pathways contributing to the trimer population would be predicted to proceed via isomers in which the central unit is linked to the other units via the same ring (see 1,8-DHN trimer $b$ in Scheme 5) and not via both rings (see 1,8-DHN trimer a in Scheme 5) because of the greater stability and spin delocalization associated with the related free-radical dimer precursor; and

(e) formation of extended quinones at each level of the oligomerization sequence may account for the blue-green chromophoric phase of the reaction.

Further elucidation of this chemistry may provide a useful background to inquire into the structural basis of the peculiar redox properties of DHN-based fungal melanin. ${ }^{4}$

\section{EXPERIMENTAL SECTION}

LFP Experiments. LFP experiments were carried out with an Applied Photophysics LK-60 laser kinetic spectrometer providing $8 \mathrm{~ns}$ pulses, using the third armonic $(355 \mathrm{~nm})$ of a

Scheme 5. Possible Oxidative Evolution of the 2,2'-Dimer of 1,8-DHN

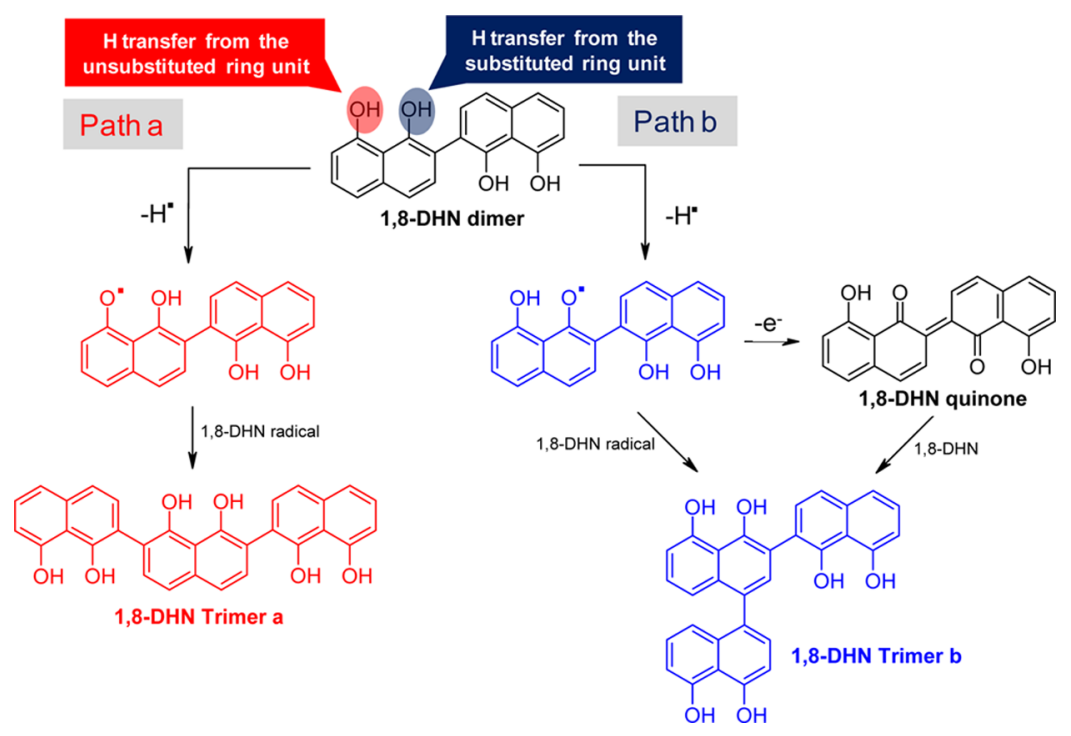


Quantel Brilliant-B Q-switched Nd:YAG laser. The laser energy was adjusted to $\leq 10 \mathrm{~mJ} /$ pulse by the use of an appropriate filter. A $3.5 \mathrm{~mL}$ Suprasil quartz cell $(10 \mathrm{~mm} \times 10 \mathrm{~mm})$ was used for all experiments. $\mathrm{N}_{2}$-saturated $\mathrm{CH}_{3} \mathrm{CN}$ solutions of hydroxynaphthalenes (1,8-DHN, 1-naphthol, 1,5-DHN, 1.5-14 $\mathrm{mM})$ and dicumyl peroxide $(1 \mathrm{M}), N$-hydroxyphthalimide $(5.0$ $\mathrm{mM})$ or 1-hydroxybenzotriazole $(9.2 \mathrm{mM})$, and naphthols $(0.1-2.0 \mathrm{mM})$ were used. All experiments were carried out at $T$ $=25+0.5^{\circ} \mathrm{C}$ under magnetic stirring. Data were collected at individual wavelengths with an Agilent Infinium oscilloscope and analyzed with the kinetic package implemented in the instrument. Rate constants were obtained by monitoring the change of absorbance at the maximum absorption wavelengths of the cumyloxyl or $\mathrm{N}$-oxyl radicals or of the product naphthoxyl radicals by averaging 3-5 values. Each kinetic trace obeyed a first-order kinetic, and second-order rate constants were obtained from the slopes of the plots of the observed rate constants $k_{\text {obs }}$ versus substrate concentration.

Isolation of the Acetylated Dimers of 1,8-DHN. The oxidation of 1,8-DHN was carried out according to a previously reported procedure. ${ }^{18}$ In brief, a solution of $1,8-\mathrm{DHN}$ (500 mg, $3.12 \mathrm{mmol})$ in acetonitrile $(20 \mathrm{~mL})$ was added to a $0.1 \mathrm{M}$ solution of phosphate buffer, $\mathrm{pH} 7.4(300 \mathrm{~mL})$ and treated under vigorous stirring with HRP $(15 \mathrm{U} / \mathrm{mL})$ and hydrogen peroxide ( $375 \mu \mathrm{L}, 1.2$ molar equivalents). The reaction mixture immediately turned into blue and after $30 \mathrm{~s}$ was quenched by the addition of a saturated solution of sodium dithionite until the mixture turned brown. After acidification with a $1 \mathrm{M}$ solution of $\mathrm{HCl}$, the mixture was extracted with ethyl acetate and the organic layer was washed with a sodium chloridesaturated solution and dried over sodium sulphate. The organic solvent was then removed under vacuum affording a brownish precipitate that was subjected to acetylation by treatment with acetic anhydride $(1 \mathrm{~mL})$ and pyridine $(50 \mu \mathrm{L})$ overnight. The resulting mixture was evaporated under a reduced pressure, and the residue was subjected to preparative thin-layer chromatography using $\mathrm{CHCl}_{3} / \mathrm{MeOH}$ 99:1 as the mobile phase to afford the acetylated dimer fraction. This latter was subjected to further chromatographic fractionation on silica gel [eluent: gradient from pure petroleum ether to petroleum ether/ethyl acetate $8: 2(\mathrm{v} / \mathrm{v})]$ leading to the acetylated $2,2^{\prime}-\left[13 \mathrm{mg}, R_{\mathrm{f}}=\right.$ 0.81 eluant chloroform/ethyl acetate $1: 1(\mathrm{v} / \mathrm{v})], 2,4^{\prime}-$ [19 mg, $R_{\mathrm{f}}=0.76$ eluant chloroform/ethyl acetate $\left.1: 1(\mathrm{v} / \mathrm{v})\right]$, and $4,4^{\prime}-$ [45 mg, $R_{\mathrm{f}}=0.73$ eluant chloroform/ethyl acetate $1: 1(\mathrm{v} / \mathrm{v})$ ] dimers of $1,8-\mathrm{DHN}$ in pure form.

Acetylated 2,2'-Dimer. ${ }^{1} \mathrm{H}$ NMR (400 $\left.\mathrm{MHz}, \mathrm{CDCl}_{3}\right) \delta$ ppm: 7.85 (d, $\left.J=7.6 \mathrm{~Hz}, \mathrm{H}-4+\mathrm{H}-4^{\prime}\right), 7.82$ (d, $J=8.4 \mathrm{~Hz}, \mathrm{H}-5$ $\left.+\mathrm{H}-5^{\prime}\right), 7.51\left(\mathrm{t}, J=7.6 \mathrm{~Hz}, \mathrm{H}-6+\mathrm{H}-6^{\prime}\right), 7.41(\mathrm{~d}, J=7.6 \mathrm{~Hz}$, $\left.\mathrm{H}-3+\mathrm{H}-3^{\prime}\right), 7.17\left(\mathrm{~d}, J=8.4 \mathrm{~Hz}, \mathrm{H}-7+\mathrm{H}-7^{\prime}\right), 2.39\left(\mathrm{~s}, \mathrm{CH}_{3}\right)$, $2.01\left(\mathrm{~s}, \mathrm{CH}_{3}\right) ;{ }^{13} \mathrm{C} \mathrm{NMR}\left(100 \mathrm{MHz}, \mathrm{CDCl}_{3}\right) \delta \mathrm{ppm}: 170.1$ $(\mathrm{C}=\mathrm{O}), 170.0(\mathrm{C}=\mathrm{O}), 145.7\left(\mathrm{C}-1+\mathrm{C}-1^{\prime}\right), 145.5(\mathrm{C}-8+\mathrm{C}-$ $\left.8^{\prime}\right), 136.7\left(\mathrm{C}-2+\mathrm{C}-2^{\prime}\right), 136.2\left(\mathrm{C}-4 \mathrm{a}+\mathrm{C} 4 \mathrm{a}^{\prime}\right), 128.7(\mathrm{C}-3+\mathrm{C}-$ $\left.3^{\prime}\right), 126.7\left(\mathrm{C}-5+\mathrm{C}-5^{\prime}\right), 126.6\left(\mathrm{C}-4+\mathrm{C}-4^{\prime}\right), 126.2(\mathrm{C}-6+\mathrm{C}-$ $\left.6^{\prime}\right), 121.1\left(\mathrm{C}-7+\mathrm{C}-7^{\prime}\right), 120.5\left(\mathrm{C}-8 \mathrm{a}+\mathrm{C}-8 \mathrm{a}^{\prime}\right), 21.1\left(\mathrm{CH}_{3}\right)$, $20.3\left(\mathrm{CH}_{3}\right) ; \mathrm{ESI}^{+}-\mathrm{MS}(\mathrm{m} / z): 509\left([\mathrm{M}+\mathrm{Na}]^{+}\right)$.

Acetylated 2,4'-Dimer. ${ }^{1} \mathrm{H}$ NMR $\left(400 \mathrm{MHz}, \mathrm{CDCl}_{3}\right) \delta$ ppm: 7.93 (d, $J=8.0 \mathrm{~Hz}, \mathrm{H}-4), 7.89$ (dd, $J=8.0,0.7 \mathrm{~Hz}, \mathrm{H}-5$ ), $7.56(\mathrm{t}, J=8.0 \mathrm{~Hz}, \mathrm{H}-6), 7.52\left(\mathrm{~d}, J=8.0 \mathrm{~Hz}, \mathrm{H}-3, \mathrm{H}-5^{\prime}\right), 7.42$ $\left(\mathrm{d}, J=8.0 \mathrm{~Hz}, \mathrm{H}-3^{\prime}\right), 7.40\left(\mathrm{t}, J=8.0 \mathrm{~Hz}, \mathrm{H}-6^{\prime}\right), 7.23(\mathrm{dd}, J=$ 8.0, $0.7 \mathrm{~Hz}, \mathrm{H}-7$ ), 7.20 (d, $J=8.0 \mathrm{~Hz}, \mathrm{H}-2^{\prime}$ ), 7.18 (dd, $J=8.0$, $\left.0.7 \mathrm{~Hz}, \mathrm{H}-7^{\prime}\right), 2.46\left(\mathrm{~s}, 2 \times \mathrm{CH}_{3}\right), 2.33\left(\mathrm{~s}, \mathrm{CH}_{3}\right), 1.76\left(\mathrm{~s}, \mathrm{CH}_{3}\right)$; ${ }^{13} \mathrm{C}$ NMR $\left(100 \mathrm{MHz}, \mathrm{CDCl}_{3}\right) \delta \mathrm{ppm:} 170.0(\mathrm{C}=\mathrm{O}), 169.9$ $(\mathrm{C}=\mathrm{O}), 169.5(\mathrm{C}=\mathrm{O}), 169.3(\mathrm{C}=\mathrm{O}), 145.9(\mathrm{C}-1), 145.8$
(C-8), 145.3 (C-8'), $145.1\left(\mathrm{C}-1^{\prime}\right), 136.7\left(\mathrm{C}-4^{\prime}\right), 136.4(\mathrm{C}-2)$, 136.0 (C-4a), $135.5\left(\mathrm{C} 4 \mathrm{a}^{\prime}\right), 128.5$ (C-3 + C-3'), 126.8 (C-5), 126.4 (C-4), 126.2 (C-5'), 126.1 (C-6), 125.9 (C-6'), 121.0 (C$\left.7+\mathrm{C}-8 \mathrm{a}^{\prime}\right), 120.2\left(\mathrm{C}-8 \mathrm{a}+\mathrm{C}-7^{\prime}\right), 120.1\left(\mathrm{C}-2^{\prime}\right), 21.6\left(\mathrm{CH}_{3}\right)$, $21.5\left(\mathrm{CH}_{3}\right), 21.0\left(\mathrm{CH}_{3}\right), 20.5\left(\mathrm{CH}_{3}\right) ; \mathrm{ESI}^{+}-\mathrm{MS}(\mathrm{m} / z): 509$ $\left([\mathrm{M}+\mathrm{Na}]^{+}\right)$.

Acetylated 4,4'-Dimer. ${ }^{1} \mathrm{H}$ NMR (400 $\left.\mathrm{MHz}, \mathrm{CDCl}_{3}\right) \delta$ ppm: 7.49 (d, J = 8.0 Hz, H-3 + H-3'), $7.3\left(\mathrm{~m}, \mathrm{H}-5+\mathrm{H}-5^{\prime}+\mathrm{H}-\right.$ $\left.6+\mathrm{H}-6^{\prime}\right), 7.25$ (d, $\left.J=8.0 \mathrm{~Hz}, \mathrm{H}-2+\mathrm{H}-2^{\prime}\right), 7.16$ (dd, $J=6.0$, $\left.2.8 \mathrm{~Hz}, \mathrm{H}-7+\mathrm{H}-7^{\prime}\right), 2.49\left(\mathrm{~s}, \mathrm{CH}_{3}\right), 2.48\left(\mathrm{~s}, \mathrm{CH}_{3}\right) ;{ }^{13} \mathrm{C} \mathrm{NMR}$ $\left(100 \mathrm{MHz}, \mathrm{CDCl}_{3}\right) \delta$ ppm: $169.7(\mathrm{C}=\mathrm{O}), 169.6(\mathrm{C}=\mathrm{O})$, $145.3\left(\mathrm{C}-8+\mathrm{C}-8^{\prime}\right), 145.1\left(\mathrm{C}-1+\mathrm{C}-1^{\prime}\right), 136.5\left(\mathrm{C}-4+\mathrm{C}-4^{\prime}\right)$, $135.9\left(\mathrm{C}-4 \mathrm{a}+\mathrm{C} 4 \mathrm{a}^{\prime}\right), 128.3\left(\mathrm{C}-3+\mathrm{C}-3^{\prime}\right), 126.3\left(\mathrm{C}-5+\mathrm{C}-5^{\prime}\right)$, $125.7\left(\mathrm{C}-6+\mathrm{C}-6^{\prime}\right), 121.1\left(\mathrm{C}-8 \mathrm{a}+\mathrm{C}-8 \mathrm{a}^{\prime}\right), 120.8\left(\mathrm{C}-7+\mathrm{C}-7^{\prime}\right)$, $120.1\left(\mathrm{C}-2+\mathrm{C}-2^{\prime}\right), 21.4\left(\mathrm{CH}_{3}\right), 21.3\left(\mathrm{CH}_{3}\right) ; \mathrm{ESI}^{+}-\mathrm{MS}(\mathrm{m} / z)$ : $509\left([\mathrm{M}+\mathrm{Na}]^{+}\right)$.

\section{ASSOCIATED CONTENT}

\section{Supporting Information}

The Supporting Information is available free of charge on the ACS Publications website at DOI: 10.1021/acsomega.8b00155.

Materials and methods; NMR and mass spectra of the isolated oligomers; one-dimensional and 2D spectra of acetylated dimers; LFP; and computational investigations (PDF)

\section{AUTHOR INFORMATION}

\section{Corresponding Author}

*E-mail: paola.manini@unina.it (P.M.).

ORCID

Paola Manini: 0000-0003-2842-5011

Massimo Bietti: 0000-0001-5880-7614

Osvaldo Lanzalunga: 0000-0002-0532-1888

Samantha Reale: 0000-0002-2773-6494

Alessandra Napolitano: 0000-0003-0507-5370

Vincenzo Barone: 0000-0001-6420-4107

Marco d'Ischia: 0000-0002-7184-0029

Notes

The authors declare no competing financial interest.

\section{ACKNOWLEDGMENTS}

This work has been carried out in the frame of the Horizon 2020-PON I\&C 2014-20-SANTRA project.

\section{REFERENCES}

(1) Bayry, J.; Beaussart, A.; Dufrêne, Y. F.; Sharma, M.; Bansal, K.; Kniemeyer, O.; Aimanianda, V.; Brakhage, A. A.; Kaveri, S. V.; KwonChung, K. J.; Latgé, J. P.; Beauvais, A. Surface Structure Characterization of Aspergillus fumigatus Conidia Mutated in the Melanin Synthesis Pathway and Their Human Cellular Immune Response. Infect. Immun. 2014, 82, 3141-3153.

(2) Kogej, T.; Wheeler, M. H.; Rižner, T. L.; Gunde-Cimerman, N. Evidence for 1,8-dihydroxynaphthalene melanin in three halophilic black yeasts grown under saline and non-saline conditions. FEMS Microbiol. Lett. 2004, 232, 203-209.

(3) Nosanchuk, J. D.; Stark, R. E.; Casadevall, A. Fungal Melanin: What do We Know About Structure? Front. Microbiol. 2015, 6, 1463.

(4) Kim, E.; Kang, M.; Tschirhart, T.; Malo, M.; Dadachova, E.; Cao, G.; Yin, J.-J.; Bentley, W. E.; Wang, Z.; Payne, G. F. Spectroelectrochemical Reverse Engineering DemonstratesThat Melanin's Redox and Radical Scavenging Activities Are Linked. Biomacromolecules 2017, $18,4084-4098$. 
(5) Avagyan, R.; Nyström, R.; Lindgren, R.; Boman, C.; Westerholm, R. Particulate hydroxy-PAH emissions from a residential wood log stove using different fuels and burning conditions. Atmos. Environ. 2016, 140, 1-9.

(6) Ashraf, H.; Husain, Q. Removal of $\alpha$-naphthol and other phenolic compounds from polluted water by white radish (Raphanus sativus) peroxidase in the presence of an additive, polyethylene glycol. Biotechnol. Bioprocess Eng. 2009, 14, 536-542.

(7) Boersma, C.; Bregman, J. D.; Allamandola, L. J. Properties of polycyclic aromatic hydrocarbons in the northwest photon dominated region of NGC 7023. I. PAH size, charge, composition and structure distribution. Astrophys. J. 2013, 769, 117.

(8) Rosenberg, M. J. F.; Berné, O.; Boersma, C. Random mixtures of polycyclic aromatic hydrocarbon spectra match interstellar infrared emission. Astron. Astrophys. 2014, 566, L4.

(9) Stock, D. J.; Peeters, E.; Choi, W. D.-Y.; Shannon, M. J. The midinfrared appearance of the galactic mini-starbust W49A. Astrophys. J. 2014, 791, 99.

(10) Shannon, M. J.; Stock, D. J.; Peeters, E. Probing the Ionization States of Polycyclic Aromatic Hydrocarbons via the 15-20 $\mu \mathrm{m}$ Emission Bands. Astrophys. J. 2015, 811, 153.

(11) Bernstein, M. P.; Dworkin, J. P.; Sandford, S. A.; Allamandola, L. J. Ultraviolet irradiation of naphthalene in $\mathrm{H}_{2} \mathrm{O}$ ice: implications for meteorites and biogenesis. Meteorit. Planet. Sci. 2001, 36, 351-358.

(12) Bernstein, M. P.; Sandford, S. A.; Allamandola, L. J.; Gillette, J. S.; Clemett, S. J.; Zare, R. N. UV Irradiation of Polycyclic Aromatic Hydrocarbons in Ices: Production of Alcohols, Quinones, and Ethers. Science 1999, 283, 1135-1138.

(13) Foti, M. C.; Johnson, E. R.; Vinqvist, M. R.; Wright, J. S.; Barclay, L. R. C.; Ingold, K. U. Naphthalene Diols: A New Class of Antioxidants Intramolecular Hydrogen Bonding in Catechols, Naphthalene Diols, and Their Aryloxyl Radicals. J. Org. Chem. 2002, 67, 5190-5196.

(14) Xi, F.; Barclay, L. R. Cooperative antioxidant effects of ascorbate and thiols with di-tert-butylcatechol during inhibited peroxidation in solution and in sodium dodecyl sulphate (SDS) micelles. Can. J. Chem. 1998, 76, 171-182.

(15) Wright, J. S.; Johnson, E. R.; DiLabio, G. A. Predicting the Activity of Phenolic Antioxidants: Theoretical Method, Analysis of Substituent Effects, and Application to Major Families of Antioxidants. J. Am. Chem. Soc. 2001, 123, 1173-1183.

(16) Wright, J. S.; Carpenter, D. J.; McKay, D. J.; Ingold, K. U. Theoretical Calculation of Substituent Effects on the $\mathrm{O}-\mathrm{H}$ Bond Strength of Phenolic Antioxidants Related to Vitamin E. J. Am. Chem. Soc. 1997, 119, 4245-4252.

(17) Lucarini, M.; Mugnaini, V.; Pedulli, G. F. Bond Dissociation Enthalpies of Polyphenols: The Importance of Cooperative Effects. J. Org. Chem. 2002, 67, 928-931.

(18) Cecchini, M. M.; Reale, S.; Manini, P.; d'Ischia, M.; De Angelis, F. Modeling Fungal Melanin Buildup: Biomimetic Polymerization of 1,8-Dihydroxynaphthalene Mapped by Mass Spectrometry. Chem.Eur. J. 2017, 23, 8092-8098.

(19) Salamone, M.; Bietti, M. Reaction Pathways of Alkoxyl Radicals. The Role of Solvent Effects on C-C Bond Fragmentation and Hydrogen Atom Transfer Reactions. Synlett 2014, 25, 1803-1816.

(20) Scheme 1 shows the direct photolysis of dicumyl peroxide following $355 \mathrm{~nm}$ laser flash photolysis. However, as suggested by a reviewer, dicumyl peroxide sensitization by photoexcited naphthalenediol cannot be ruled out as an additional pathway for cumyloxyl radical generation. We thank this reviewer for drawing our attention on this point. For a recent example of photosensitized homolysis of dicumyl peroxide see: Walalawela, N.; Greer, A. Heterogeneous photocatayltic deperoxidation with UV and visible light. J. Phys. Org. Chem. 2018, 108, No. e3807.

(21) Das, P. K.; Encinas, M. V.; Steenken, S.; Scaiano, J. C. Reaction of tert-Butoxy Radicals with Phenols. Comparison with the Reactions of Carbonyl Triplets. J. Am. Chem. Soc. 1981, 103, 4162-4166.

(22) Baciocchi, E.; Bietti, M.; Gerini, M. F.; Lanzalunga, O. ElectronTransfer Mechanism in the N-Demethylation of N,N-Dimethylanilines by the Phthalimide-N-oxyl Radical. J. Org. Chem. 2005, 70, 51445149.

(23) Baciocchi, E.; Bietti, M.; Di Fusco, M.; Lanzalunga, O. A Kinetic Study of the Electron-Transfer Reaction of the Phthalimide-N-oxyl Radical (PINO) with Ferrocenes. J. Org. Chem. 2007, 72, 8748-8754.

(24) Baciocchi, E.; Bietti, M.; Di Fusco, M.; Lanzalunga, O.; Raponi, D. Electron-Transfer Properties of Short-Lived N-Oxyl Radicals. Kinetic Study of the Reactions of Benzotriazole-N-oxyl Radicals with Ferrocenes. Comparison with the Phthalimide-N-oxyl Radical. J. Org. Chem. 2009, 74, 5576-5583.

(25) Baciocchi, E.; Bietti, M.; Lanzalunga, O.; Lapi, A.; Raponi, D. NDemethylation of N,N-Dimethylanilines by the Benzotriazole N-Oxyl Radical: Evidence for a Two-Step Electron Transfer-Proton Transfer Mechanism. J. Org. Chem. 2010, 75, 1378-1385.

(26) Baciocchi, E.; Bietti, M.; D’Alfonso, C.; Lanzalunga, O.; Lapi, A.; Salamone, M. One-electron oxidation of ferrocenes by short-lived $\mathrm{N}$ oxyl radicals. The role of structural effects on the intrinsic electron transfer reactivities. Org. Biomol. Chem. 2011, 9, 4085-4090.

(27) Galli, C.; Gentili, P.; Lanzalunga, O.; Lucarini, M.; Pedulli, G. F. Spectrophotometric, EPR and kinetic characterisation of the $>\mathrm{N}-\mathrm{O}^{\bullet}$ radical from 1-hydroxybenzotriazole, a key reactive species in mediated enzymatic oxidations. Chem. Commun. 2004, 2356-2357.

(28) Recupero, F.; Punta, C. Free Radical Functionalization of Organic Compounds Catalyzed by N-Hydroxyphthalimide. Chem. Rev. 2007, 107, 3800-3842.

(29) D’Alfonso, C.; Bietti, M.; DiLabio, G. A.; Lanzalunga, O.; Salamone, M. Reactions of the Phthalimide N-Oxyl Radical (PINO) with Activated Phenols: The Contribution of $\pi$-Stacking Interactions to Hydrogen Atom Transfer Rates. J. Org. Chem. 2013, 78, 10261037.

(30) Mazzonna, M.; Bietti, M.; Di Labio, G. A.; Lanzalunga, O.; Salamone, M. Importance of $\pi$-Stacking Interactions in the Hydrogen Atom Transfer Reactions from Activated Phenols to Short-Lived NOxyl Radicals. J. Org. Chem. 2014, 79, 5209-5218.

(31) Adamo, C.; Barone, V. Toward reliable density functional methods without adjustable parameters: The PBE0 model. J. Chem. Phys. 1999, 110, 6158-6170.

(32) Miertuš, S.; Scrocco, E.; Tomasi, J. Electrostatic interaction of a solute with a continuum. A direct utilizaion of $\mathrm{AB}$ initio molecular potentials for the prevision of solvent effects. J. Chem. Phys. 1981, 55, $117-129$.

(33) Cossi, M.; Scalmani, G.; Rega, N.; Barone, V. New developments in the polarizable continuum model for quantum mechanical and classical calculations on molecules in solution. J. Chem. Phys. 2002, 117, 43-54.

(34) Scalmani, G.; Barone, V.; Kudin, K. N.; Pomelli, C. S.; Scuseria, G. E.; Frisch, M. J. Achieving linear-scaling computational cost for the polarizable continuum model of salvation. Theor. Chem. Acc. 2004, $111,90-100$.

(35) Tomasi, J.; Mennucci, B.; Cammi, R. Quantum Mechanical Continuum Solvation Models. Chem. Rev. 2005, 105, 2999-3094.

(36) Marenich, A. V.; Cramer, C. J.; Truhlar, D. G. Universal Solvation Model Based on Solute Electron Density and on a Continuum Model of the Solvent Defined by the Bulk Dielectric Constant and Atomic Surface Tensions. J. Phys. Chem. B 2009, 113, 6378-6396.

(37) Stratmann, R. E.; Scuseria, G. E.; Frisch, M. J. An efficient implementation of time-dependent density-functional theory for the calculation of excitation energies of large molecules. J. Chem. Phys. 1998, 109, 8218-8224.

(38) Bauernschmitt, R.; Ahlrichs, R. Treatment of electronic excitations within the adiabatic approximation of time dependent density functional theory. Chem. Phys. Lett. 1996, 256, 454-464.

(39) Casida, M. E.; Jamorski, C.; Casida, K. C.; Salahub, D. R. Molecular excitation energies to high-lying bound states from timedependent density-functional response theory: Characterization and correction of the time-dependent local density approximation ionization threshold. J. Chem. Phys. 1998, 108, 4439-4449. 
(40) Adamo, C.; Scuseria, G. E.; Barone, V. Accurate excitation energies from time-dependent density functional theory: assessing the PBE0 model. J. Chem. Phys. 1999, 111, 2889-2899.

(41) Scalmani, G.; Frisch, M. J.; Mennucci, B.; Tomasi, J.; Cammi, R.; Barone, V. Geometries and properties of excited states in the gas phase and in solution: Theory and application of a time-dependent density functional theory polarizable continuum model. J. Chem. Phys. 2006, $124,1-15$. 